\title{
Using Unconditional Logistic Regression to Assess Prostate Cancer Risk Factors: Practical Messages for Public Health
}

\author{
Rasool Roozegar ${ }^{1}$, Alireza Khoshdel ${ }^{2}$ \\ ${ }^{1}$ Department of Statistics, Yazd University, Yazd, Iran \\ ${ }^{2}$ Department of Epidemiology, Aja University of Medical Sciences, Tehran, Iran
}

\begin{abstract}
Objectives: Risk assessment, early diagnosis and timely treatment of prostate cancer have a great role in survival and quality of life of patients. Assuming a different cancer epidemiology in developing countries, this study aimed to identify risk factors for prostate cancer in southern Iran to be implicated in Asian developing countries' public health systems.

Methods: A case-control study of prostate cancer ( $\mathrm{PCa}$ ) was undertaken in two Iranian provinces. Ninety eight Cases with histologically confirmed incident disease and 98 control patients treated in the same hospitals for other minor diseases (2005-2010) were included. The data about demographic, socio-economic, sexual and biomedical variables were modeled through unconditional Logistic regression (using the EGRET and SPSS) as well as odds ratios and 95\% confidence intervals. Results: There was no significant difference between the groups in terms of anthropometric variables (including height and BMI), marital, birth order of children, sexual function, history of STD and testosterone related phenotype between the two groups. However urban residency, smoking, patient's age and family history of prostate cancer were determined as significant risk factors for $\mathrm{PCa}$ $(\mathrm{P}=0.006, \mathrm{P}=0.03, \mathrm{P}=0.008$ and $\mathrm{P}=0.006$, respectively). Among the reported past disease history, only the history of $\mathrm{TB}$ disease was a significant determinant $(\mathrm{OR}=2.08, \mathrm{P}=0.01)$.

Conclusion: The results are evidence against a relationship between anthropometric measures, marital status, sexual behavior, alcohol consumption and past medical history (including history of STD) and in favor of a relationship of age, family history of prostate cancer, urban residency and smoking with prostate cancer.

Keywords: Unconditional logistic regression, Prostate cancer, Risk factors, age, smoking, family history.
\end{abstract}

\section{Introduction}

Prostate cancer $(\mathrm{PCa})$ is known as a one of the most frequent cancers among men in the world. This cancer along with colorectal cancer follows lung cancer, i.e. as the second common cause of cancer death among men in developed countries [1-6]. However, its incidence is much lower 
in Asian countries. For example, it is ranked as the seventh cause of cancer mortality in Iranian men, though underestimation is expected and conflicting reports have been presented. [7]. Longterm incidence of and mortality from prostate cancer have been slowly increasing in the most communities, but new approaches for diagnostic methods and revised policies for screening and treatment has been developed in recent years [8]. Long term complications of PCa treatment such as urinary incontinence, sexual dysfunction and inflammation caused by radiation have a negative impact on the quality of patient's life [9].

In various studies, contradictory results have been reported about the risk factors for prostate cancer in different age groups, although age was a determinant factor in almost all studies [10]. High serum testosterone [11] and semi-insulin growth factor [12] are implicated in the development of prostate cancer. A long list of possible risk factors has been introduced for incidence of prostate cancer including age, geographic region, and family history of this disease, race, social and individual habits such as smoking, alcohol consumption, low fruit and vegetable intake and high dietary fat [13-15]. Also, there are some reports demonstrating association of PCa with history of prostatitis and sexually transmitted diseases, low physical activity, vasectomy history, occupational exposure to insecticide chemicals and cadmium, sexual activity and obesity. However, there is no consensus about these factors and there might be differences between communities in terms of their impact.

In order to re-explore the potential risk factors for prostate cancer, this case-control study was conducted in the south of Iran. The result could be more applicable for Asian countries than data from Western developed countries.

\section{Methods}

This case-control study included 107 patients with histologically confirmed incident disease from the four major hospitals of southern Iranian Hospitals (Bandar Abbas -Hormozgan Province and also Namazi hospital in Shiraz from Fars Province). Access to the information of 9 patients due to the lack of their medical records availability or changing of their address was impossible so finally 98 patients were enrolled in the study. Patients in the control group, who were matched with cases based on age group (10 years intervals) and social-economic status, were selected from the same hospitals. Patients with prior history of malignancy and BPH were excluded from the study. Consequently, 98 patients out of 107 patients remained as controls in the study. All medical records were evaluated and certain information about demographic variables and information gaps were filled by taking information via telephone conversation, and face to face interviews. This study was approved by the ethics committee of our University.

The unconditional logistic regression (univariate and multivariate) was used to assess the association with risk factors [16]. In this method, the dependent variable was considered as a dichotomous scale (disease-not disease) and independent variables could be either continuous or discrete. Odds ratio (OR) and 95\% confidence interval were also estimated. For this purpose, EGRET and SPSS software were used with significance level less than 0.05. In this Section, Neyman's smooth test (NST) and the extended Neyman's smooth test (ENST) are explained. 


\section{Results}

By examining the various possible factors in univariate analyses, there wasn't any significant difference between cases and controls in term of height and body mass index (BMI) variables. (Table1). Then, all subsequent analyzes considered regardless of height and BMI variables. Concerning demographic characteristics, as demonstrated in the Table 2, there wasn't any significant difference with respect to marital status, number of offspring and birth order in the parental family between the case and control group, but urban residency was significantly higher in the diseased group.

To control for potential confounding effects between the potential risk factors, multivariate unconditional regression analysis was conducted including age and those variables associated with prostate cancer at the $\mathrm{P}<0.05$ level. Retaining only those selected variables or personal habits associated with prostate cancer cases at the $\mathrm{P}<0.05$ level produced a final model with three risk factors. Table 3 indicates the frequency distributions of patients in both groups with respect to some selected variables. With the exception of variables such as smoking, age and history of prostate cancer in close relatives, there was not any evidence to show that other variables could be a risk factor of prostate cancer. Heavy smokers appear to be at higher risk than non-smokers and this increasing trend is statistically significant $(\mathrm{P}=0.03)$. Also the risk of disease increase with age and this trend is statistically significant $(\mathrm{P}=0.008)$. The odds ratio of developing prostate cancer in those who had a history of this disease in their close relatives was more than 3 times greater than those who hadn't such a family history of cancer in their close relatives $(\mathrm{P}=0.006)$.

In Table 4, the number of past surgical operations including vasectomy was not significantly influential in the disease. Table 5 indicates the comparisons between the reported illnesses by patients. With the exception of tuberculosis, no significant correlation was observed.

Patients with prostate cancer and controls subject were asked to report the frequency of their weekly sexual intercourse in the two recent decades of their lives. Many of the subjects refused to answer the question and the rest of them provided the vague answer. From 42 patients with prostate cancer who responded to this question, 24 patients (58\%) reported being overactive (4 or more sexual intercourse per week), versus 9 overactive persons (62\%) out of 15 control individuals who answered to this question. This difference was statistically significant $(\mathrm{P}=0.009)$ and was not influenced by variables such as gender, infectious disease and suggest a negative relationship between sexual activity and the risk of prostate cancer.

\section{Discussion}


Few studies been conducted on the risk factors for prostate cancer in the Iranian community [17]. Our case-control study investigated potential associations with prostate cancer in a southern province of Iran and found ten risk factors meriting careful consideration. Given several controversial risk factors, this study had sufficient power to determine the common risk factors of prostate cancer. To minimize the potential bias, cases and controls were examined under the same condition. There isn't any evidence to identify the birth order and the number of children as risk factors for prostate cancer in our study which was in agreement with some of previous studies [8]. Also, our study did not show any association with marital status, possibly because of a matched status between the cases and controls. However, a Few studies demonstrated these variables as affecting factors $[8,18]$. In parallel to some studies [19] our findings suggest that some aspects of urban life may increase the risk of prostate cancer.

While androgens may play an important role in increasing baldness and the high levels of testosterone in the blood are positively associated with prostate cancer risk [9], we could not find any relationship between androgenic phenotypes including baldness and chest hair with incident prostate cancer. This is in contrast to another study in Japan showed the positive relationship between these two variables [20]. Again, this might be due to similarities between the cases and controls in our study in their male appearance.

In respect to dietary factors, neither our investigation nor previous studies found any association between tea consumption and prostate cancer risk [18]. Alcohol drinking was not associated to PCa risk in the present study. This is in contrast to a prospective cohort study in US demonstrated an increased risk of prostate cancer in men who consumed more than three alcoholic drinks per day [21]. There is some evidence that certain foods may slow down the growth of prostate cancer or reduce the risk of it returning after treatment. At the moment this evidence is limited and more research is needed to show clearly how different foods can help [22-24].

It has been assumed that infectious disease and sexual hyperactivity increase the risk of prostate cancer [14]. Many epidemiological findings are consistent with this hypothesis while the finding of this study and some other previous studies $[25,26]$ didn't find any relationship between risk of prostate cancer and sexual hyperactivity and the other infectious disease. Although we observed an inverse relationship between sexual activity and prostate cancer, it could be due to a minimal (but significant) age differences between the two groups.

There are contradictory reports that diabetes positively and in some cases negatively associated with prostate cancer [27]. Since diabetes reduce the testosterone levels, the inverse association between diabetes and prostate cancer does biologically sound. However, our study did not demonstrate any association between diabetes and risk of prostate cancer. Based on empirical evidence, a similar situation exists in the case of liver disease. This disease associated with high levels of estrogen or low level of androgen. However epidemiological studies including ours have not demonstrated any association between liver disease and prostate cancer yet [14]. In contrast, the effect of variables such as age, smoking and family history of prostate disease is confirmed in this study. The significant positive association between prostate cancer and allergy or asthma variables contradicts with the inverse association found in several other studies between these conditions, on the one hand, and other forms of cancer, on the other $[20,28]$. 
Recently, our group conducted a survival analysis study to build a risk score and determine a valid cut-off point for the score in order to discriminate high, moderate and low risk individuals for PCa. In that research (not published yet), only age and PSA remained as independent determinants of the score. Consequently, it was concluded that screening by a single marker would not be sufficiently valid. Rather, researchers must promote using multivariate scores (the Prostate Risk Score is available via Research Gate). However, more studies are required to prospectively validate the score.

In Conclusion, Age, family history and smoking as well as urban residency were independent risk factors for PCa in our study group. However many claimed factors in previous studies had no relationship with PCa in this study.

\section{Acknowledgment}

We would like to thank the Editor, Referee and all staff of the AJA University of Medical Sciences, especially Dr Dormanesh. We also express our sincere appreciations to Shahid Mohammadi Hospital in Bandar Abbas and Namazi Hospital in Shiraz in data collection. This study was supported by AJA University of Medical Sciences and also Yazd University.

\section{Conflict of Interest:}

None declared.

\section{References}

[1] American cancer society, cancer facts and figures 2012, American cancer society, Atlanta 2012.

[2] Salem S, Salahi, M, Mohseni, M et al. Major dietary factors and prostate cancer risk: a prospective multicenter case-control study. Nutr. Cancer 2011; 63: 21-7.

[3] Mazdak H, Mazdak M, Jamali, L, Keshteli AH. Determination of prostate cancer risk factors in Isfahan, Iran: a case-control study. Med. Arh. 2012; 66: 45-48.

[4] Li Y, Ahmad A, Kong D, Bao B, Sarkar FH. Recent progress on nutraceutical research in prostate cancer. Cancer Metastasis Rev. 2013; 1-12.

[5] Zhou XF, Ding ZS, Liu NB. Allium Vegetables and Risk of Prostate Cancer: Evidence from 132,192 Subjects. Asian Pac. J. Cancer Prev. 2013; 14: 4131-4.

[6] Jardim Paz MFC, Monte BS, Neto JDJR, Tapety FI, Sousa CMMD, Melo Cavalcante AADC. Correlations between risk factors for prostate cancer: an epidemiological analysis. R. Pesq. Cuid. Fundam. Online 2014; 5: 187-99.

[7] Hosseini M, Seyed Alinaghi S, Mahmoudi M, McFarland W. A case-control study of risk factors for prostate cancer in Iran. Acta Med. Iran 2010; 48: 61-6.

[8] Nomura AMY, Kolonel LN. Prostate cancer: a current perspective. Amer. J. Epidemiol. 1991; 13: 200-27. 
[9] Gann PH, Hennekens CH, Ma J, Longcope C, Stampfer MJ. Prostate study of sex hormone levels and risk of prostate cancer. J. Nat. Cancer Inst. 1996; 88: 1118-26.

[10] Mantzoros CS, Tzonou A, Signorello LB, Stampfer M, Trichoppulos D, A dami HO. Insullin-like growth factor 1 in relation to prostate cancer and benign prostatic hyperplasia. Brit. J. Cancer 1997; 76: 1115-8.

[11] Jabel Amel P, Bahadori M. Early detection of prostatic cancers. J. Med. Counc. I.R. Iran 1999; 3: 231-8. [Article in Persian]

[12] Godley PA, Schell MJ. Adjusted odds ratios under nondifferential misclassification: application to prostate cancer. J. Clin. Epidemiol. 1999; 52: 129-36.

[13] King H, Diamand E, Lilienfeid AM. Some epidemiological aspects of cancer of the prostate. J. Chronic Dis. 1963; 16: 117-53.

[14] Wynder EL, Mabuchi K, Whitmore WF. Epidemiology of cancer of the prostate. Cancer 1971; 28: 344-60.

[15] Owen WL. Cancer of the prostate: A literature review. J. Chronic Dis. 1976; 29: 89-114.

[16] Clayton D, Hills M. Statistical models in epidemiology. Oxford University Press. 1994; pp: 290-7.

[17] Pourmand Gh, Salem S, Mehrsai A et al. The risk factors of Prostate cancer: A multicentric case-control study in Iran. Asian Pac. J. Cancer Prev. 2007; 8: 422-28.

[18] Andersson SO, Baron J, Bergström R, Lindgren C, Wolk A, Adami HO. Lifestyle factors and prostate cancer risk: a case-control study in Sweden. Cancer Epidemiol. Biomarkers Prevent. 1996; 5: 509-13.

[19] Andersson SO, Baron J, Wolk A, Lindgren C, Bergström R, Adami HO. Early life risk factors for prostate cancer: a population-based case- control study in Sweden. Cancer Epidemiol. Biomarkers Prevent. 1995; 4: 187-92.

[20] Oishi K, Okada K, Yoshida O et al. Case-control study of prostatic cancer in Kyoto, Japan: demographic and some lifestyle risk factors. Prostate 1989; 14: 117-22.

[21] Sesso HD, Paffenbarger RS, Lee IM. Alcohol consumption and risk of prostate cancer: The Harvard Alumni Health Study. Int. J. Epidemiol. 2001; 30: 749-55.

[22] Irani J, Lefebvre O, Murat F, Dahmani L, Dore B. Obesity in relation to prostate cancer risk: comparison with a population having benign prostatic hyperplasia. BJU International 2003; 91: 482-4.

[23] Pelser C, Mondul AM, Hollenbeck AR, Park Y. Dietary fat, fatty acids, and risk of prostate cancer in the NIH-AARP diet and health study. Cancer Epidemiol. Biomarkers Prev. 2013; 22: 697-707.

[24] Hori S, Butler E, McLoughlin J. Prostate cancer and diet: food for thought? BJU International 2011; 107: 1348-59.

[25] Sutcliffe, S. Sexually transmitted infections and risk of prostate cancer: review of historical and emerging hypotheses. Future Oncol. 2010; 6: 1289-311.

[26] Ahmadi H, Allameh F, Baradaran N et al. Circulating sex hormones play no role in the association between sexual activity and the risk of prostate cancer. J. Sex. Med. 2011; 8: 905-13.

[27] Leitmann MF, Platz EA, Stampfer MJ, Willett WC, Giovannucci E. Ejaculation frequency and subsequent risk of prostate cancer. JAMA. 2004; 291: 1578-786.

[28] Ewings P, Bowie C. A case-control study of cancer of the prostate in Somerset and east Devon. Brit. J. Cancer, 1996; 74: 661-6. 
Table 1: Distribution of 98 patients with prostate cancer and 98 controls by age, height and body mass index (BMI)

\begin{tabular}{|c|c|c|c|c|c|c|}
\hline \multirow{2}{*}{ Variables } & \multirow{2}{*}{$\frac{\text { Cases }}{\text { Number (Percent) }}$} & \multirow{2}{*}{$\begin{array}{c}\text { Controls } \\
\text { Number (Percent) }\end{array}$} & \multirow{2}{*}{$\begin{array}{c}\text { Odds Ratio } \\
\text { (OR) }\end{array}$} & \multirow{2}{*}{$95 \% \mathrm{CI}$} & \multicolumn{2}{|c|}{ Trend Test } \\
\hline & & & & & $\chi^{2}$ & P-Value \\
\hline \multicolumn{7}{|l|}{ Age (years) } \\
\hline$<60$ & $6(6.1)$ & 27 (27.6) & 1 & & 8.76 & 0.008 \\
\hline $60-69$ & $41(41.8)$ & $18(18.4)$ & 3.2 & $2.6-4.9$ & & \\
\hline $70-79$ & 35 (35.7) & 31 (31.6) & 1.2 & $0.6-1.8$ & & \\
\hline $80<=$ & $16(16.4)$ & $22(22.4)$ & 0.67 & $0.23-0.91$ & & \\
\hline \multicolumn{7}{|l|}{ Height $(\mathrm{cm})$} \\
\hline$<165$ & $16(16.3)$ & $13(13.4)$ & 1 & & 0.42 & 0.53 \\
\hline $165-169$ & $27(27.6)$ & 27 (27.6) & 0.95 & $0.5-1.65$ & & \\
\hline $170-174$ & $30(30.6)$ & 31 (31.6) & 0.9 & $0.53-1.6$ & & \\
\hline $175<=$ & $25(25.5)$ & 27 (27.6) & 0.85 & $0.45-1.5$ & & \\
\hline \multicolumn{7}{|l|}{ BMI $\left(\mathrm{kg} / \mathrm{m}^{2}\right)$} \\
\hline$<20$ & $3(3.1)$ & $4(4.1)$ & 1 & & 0.029 & 0.85 \\
\hline $20-21.99$ & $8(8.2)$ & $9(9.2)$ & 0.88 & $0.4-1.56$ & & \\
\hline $22-23.99$ & $19(19.4)$ & $18(18.4)$ & 1.07 & $0.35-1.85$ & & \\
\hline $24-25.99$ & $30(30.6)$ & $22(22.4)$ & 1.52 & $0.85-2.1$ & & \\
\hline $26-27.99$ & $17(17.3)$ & $22(22.4)$ & 0.73 & $0.32-1.1$ & & \\
\hline $28-29.99$ & $11(11.2)$ & $13(13.3)$ & 0.83 & $0.30-1.2$ & & \\
\hline $30-31.99$ & $5(5.1)$ & $5(5.1)$ & 0.95 & $0.45-1.6$ & & \\
\hline $32<=$ & $5(5.1)$ & $5(5.1)$ & 0.95 & $0.49-1.63$ & & \\
\hline
\end{tabular}


448 Using Unconditional Logistic Regression to Assess Prostate Cancer Risk Factors: Practical Messages for Public Health

Table 2: Distribution of 98 patients with prostate cancer and 98 controls by demographic characteristics

\begin{tabular}{|c|c|c|c|c|c|c|}
\hline \multirow{2}{*}{ Variables } & \multirow{2}{*}{$\begin{array}{c}\text { Cases } \\
\text { Number (Percent) }\end{array}$} & \multirow{2}{*}{$\begin{array}{c}\text { Controls } \\
\text { Number (Percent) }\end{array}$} & \multirow{2}{*}{$\begin{array}{l}\text { Odds Ratio } \\
\text { (OR) }\end{array}$} & \multirow{2}{*}{$95 \% \mathrm{CI}$} & \multicolumn{2}{|c|}{ Trend Test } \\
\hline & & & & & $\chi^{2}$ & P-Value \\
\hline \multicolumn{7}{|l|}{ Usual residence } \\
\hline Rural & $33(33.7)$ & $49(50)$ & 1 & & 6.65 & 0.006 \\
\hline Urban & $65(66.3)$ & $49(50)$ & 1.97 & $1.2-3.1$ & & \\
\hline \multicolumn{7}{|c|}{ Birth order } \\
\hline 1 & $27(27.6)$ & $27(27.6)$ & 1 & & 0.13 & 0.89 \\
\hline 2 & $19(19.4)$ & $22(22.4)$ & 0.83 & $0.41-1.1$ & & \\
\hline 3 & $16(16.3)$ & $18(18.4)$ & 0.87 & $0.45-1.15$ & & \\
\hline 4 & $11(11.2)$ & $9(9.2)$ & 1.25 & $0.85-1.65$ & & \\
\hline $5<=$ & $25(25.5)$ & $22(22.4)$ & 1.18 & $0.83-1.44$ & & \\
\hline \multicolumn{7}{|c|}{ Marital status } \\
\hline single & $3(3.1)$ & $4(4.1)$ & 1 & & 1.04 & 0.29 \\
\hline married & $95(96.9)$ & $94(95.9)$ & 0.96 & $0.45-1.61$ & & \\
\hline \multicolumn{7}{|c|}{ Number of offspring } \\
\hline 0 & $11(11.2)$ & $9(9.2)$ & 1 & & 0.04 & 0.73 \\
\hline 1 & $16(16.3)$ & $18(18.4)$ & 0.87 & $0.49-1.12$ & & \\
\hline 2 & $41(41.7)$ & $35(35.7)$ & 1.29 & $0.92-1.78$ & & \\
\hline 3 & $16(16.3)$ & $18(18.4)$ & 0.87 & $0.5-1.16$ & & \\
\hline $4<=$ & $14(14.3)$ & $18(18.4)$ & 0.74 & $0.63-1.1$ & & \\
\hline
\end{tabular}


Table 3: Distribution of 98 patients with prostate cancer and 98 controls by personal characteristics and habits

\begin{tabular}{|c|c|c|c|c|c|c|}
\hline \multirow{2}{*}{ Variables } & \multirow{2}{*}{$\begin{array}{c}\text { Cases } \\
\text { Number (Percent) }\end{array}$} & \multirow{2}{*}{$\begin{array}{c}\text { Controls } \\
\text { Number (Percent) }\end{array}$} & \multirow{2}{*}{$\begin{array}{l}\text { Odds Ratio } \\
\quad \text { (OR) }\end{array}$} & \multirow{2}{*}{$95 \% \mathrm{CI}$} & \multicolumn{2}{|c|}{ Trend Test } \\
\hline & & & & & $\chi^{2}$ & P-Value \\
\hline \multicolumn{7}{|l|}{ Age (year) } \\
\hline$<60$ & $6(6.1)$ & $27(27.6)$ & 1 & & 8.76 & 0.008 \\
\hline $60-69$ & $41(41.8)$ & $18(18.4)$ & 3.2 & $2.8-5.9$ & & \\
\hline $70-79$ & $35(35.8)$ & $31(31.6)$ & 1.7 & $1.1-3.4$ & & \\
\hline $80<=$ & $16(16.3)$ & $22(22.4)$ & 0.67 & $.39-1.28$ & & \\
\hline \multicolumn{7}{|l|}{ Baldness } \\
\hline No & $16(16.3)$ & $13(13.3)$ & 1.28 & $0.81-1.81$ & - & - \\
\hline Frontal & $49(50)$ & $49(50)$ & 1 & $0.75-1.3$ & 0.15 & 0.63 \\
\hline Vertex & $33(33.7)$ & $36(36.7)$ & 0.87 & $0.53-1.17$ & 0.61 & 0.36 \\
\hline \multicolumn{7}{|l|}{ Chest hair } \\
\hline None & $8(8.2)$ & $4(4.1)$ & 1 & & 0.37 & 0.63 \\
\hline Some & $57(58.2)$ & $67(68.4)$ & 0.63 & $0.39-1.12$ & & \\
\hline Plenty & $33(33.7)$ & $27(27.6)$ & 1.32 & $0.92-1.78$ & & \\
\hline \multicolumn{7}{|l|}{ Family history } \\
\hline No & $84(87.5)$ & $92(95.8)$ & 1 & & 9.61 & 0.006 \\
\hline Yes & $12(12.5)$ & $4(4.2)$ & 3.28 & $1.89-6.85$ & & \\
\hline \multicolumn{7}{|c|}{$\begin{array}{c}\text { Sexually transmitted } \\
\text { disease }\end{array}$} \\
\hline None & $82(83.7)$ & $85(86.7)$ & 0.78 & $0.35-1.12$ & - & - \\
\hline Gonorrhea & $11(11.2)$ & $9(9.2)$ & 0.93 & $0.57-1.23$ & 0.62 & 0.41 \\
\hline Other & $5(5.1)$ & $4(4.1)$ & 0.86 & $0.69-1.11$ & 0.12 & 0.73 \\
\hline \multicolumn{7}{|c|}{ Smoking (cigarettes/day) } \\
\hline Never & $33(33.7)$ & $27(27.6)$ & 1.34 & $0.79-1.88$ & - & - \\
\hline $1-19$ & $24(24.5)$ & $18(18.4)$ & 1.74 & $1.25-2.1$ & 0.008 & 0.96 \\
\hline $20<=$ & $41(41.8)$ & $53(54)$ & 0.91 & $0.65-1.32$ & 4.41 & 0.03 \\
\hline \multicolumn{7}{|l|}{ Tea (cups/day) } \\
\hline None & $11(11.2)$ & $5(5.1)$ & 1 & & 0.05 & 0.76 \\
\hline$<1$ & $6(6.1)$ & $9(9.2)$ & 0.64 & $0.38-1.18$ & & \\
\hline $1-2<$ & $27(27.6)$ & $22(22.4)$ & 1.31 & $1.09-1.79$ & & \\
\hline $2-3<$ & $35(35.7)$ & $40(40.8)$ & 0.81 & $0.42-1.28$ & & \\
\hline $3<=$ & $19(19.4)$ & $22(22.4)$ & 0.83 & $0.33-1.31$ & & \\
\hline \multicolumn{7}{|c|}{ Alcohol drinking } \\
\hline No & $89(92.7)$ & $88(91.6)$ & 1 & & 0.62 & 0.18 \\
\hline Yes & $7(7.3)$ & $8(8.4)$ & 0.87 & $0.69-1.45$ & & \\
\hline
\end{tabular}


450 Using Unconditional Logistic Regression to Assess Prostate Cancer Risk Factors: Practical Messages for Public Health

Table 4: Past surgical operations reported by 98 patients with prostate cancer and 98 controls

\begin{tabular}{|c|c|c|c|c|c|c|}
\hline \multirow{2}{*}{$\begin{array}{c}\text { Surgical } \\
\text { Operations }\end{array}$} & \multirow{2}{*}{$\begin{array}{c}\text { Cases } \\
\text { Number (Percent) }\end{array}$} & \multirow{2}{*}{$\begin{array}{c}\text { Controls } \\
\text { Number (Percent) }\end{array}$} & \multirow{2}{*}{$\begin{array}{l}\text { Odds Ratio } \\
\text { (OR) }\end{array}$} & \multirow{2}{*}{$95 \% \mathrm{CI}$} & \multicolumn{2}{|c|}{ Contrast Test } \\
\hline & & & & & $\chi^{2}$ & P-Value \\
\hline \multicolumn{7}{|c|}{ Tonsillectomy } \\
\hline No & $82(83.7)$ & $85(86.7)$ & 1 & & 1.12 & 0.31 \\
\hline Yes & $16(16.3)$ & $13(13.3)$ & 0.78 & $0.69-1.78$ & & \\
\hline \multicolumn{7}{|c|}{ Vasectomy } \\
\hline No & $93(94.9)$ & 95 (96.9) & 1 & & 1.39 & 0.18 \\
\hline Yes & $5(5.1)$ & $3(3.1)$ & 0.69 & $0.23-1.15$ & & \\
\hline \multicolumn{7}{|c|}{ Appendectomy } \\
\hline No & $71(72.4)$ & $76(77.6)$ & 1 & & 1.69 & 0.15 \\
\hline Yes & $27(27.6)$ & $22(22.4)$ & 0.91 & $0.63-1.96$ & & \\
\hline \multicolumn{7}{|c|}{ Cholecystectomy } \\
\hline No & $93(94.9)$ & $94(95.9)$ & 1 & & 0.036 & 0.98 \\
\hline Yes & $5(5.1)$ & $4(4.1)$ & 0.83 & $0.35-1.8$ & & \\
\hline \multicolumn{7}{|c|}{ Stomach ulcer } \\
\hline No & $95(96.9)$ & $94(95.9)$ & 1 & & 0.35 & 0.61 \\
\hline Yes & $3(3.1)$ & $4(4.1)$ & 0.84 & $0.49-1.85$ & & \\
\hline \multicolumn{7}{|c|}{ Duodenal ulcer } \\
\hline No & $95(96.9)$ & $94(95.9)$ & 1 & & 0.35 & 0.61 \\
\hline Yes & $3(3.1)$ & $4(4.1)$ & 0.84 & $0.68-1.9$ & & \\
\hline \multicolumn{7}{|c|}{ Hemorrhoids } \\
\hline No & $95(96.9)$ & $98(100)$ & 1 & & 1.75 & 0.08 \\
\hline Yes & $3(3.1)$ & $0(0)$ & 1.1 & $0.93-2.2$ & & \\
\hline \multicolumn{7}{|c|}{ Hernias } \\
\hline No & $79(80.6)$ & $80(81.6)$ & 1 & & 0.04 & 0.81 \\
\hline Yes & $19(19.4)$ & $18(18.4)$ & 0.67 & $0.43-1.12$ & & \\
\hline \multicolumn{7}{|c|}{ Kidney stones } \\
\hline No & 95 (96.9) & $89(90.8)$ & 1 & & 0.09 & 0.51 \\
\hline Yes & $3(3.1)$ & $9(9.2)$ & 0.81 & $0.49-1.65$ & & \\
\hline
\end{tabular}


Table 5: Disease reported by 98 patients with prostate cancer and 98 controls

\begin{tabular}{|c|c|c|c|c|c|c|}
\hline \multirow{2}{*}{ Disease } & \multirow{2}{*}{$\begin{array}{c}\text { Cases } \\
\text { Number (Percent) }\end{array}$} & \multirow{2}{*}{$\begin{array}{c}\text { Controls } \\
\text { Number (Percent) }\end{array}$} & \multirow{2}{*}{$\begin{array}{l}\text { Odds Ratio } \\
\quad \text { (OR) }\end{array}$} & \multirow{2}{*}{$95 \% \mathrm{CI}$} & \multicolumn{2}{|c|}{ Contrast Test } \\
\hline & & & & & $\chi^{2}$ & P-Value \\
\hline \multicolumn{7}{|l|}{ Hepatitis } \\
\hline No & $90(91.8)$ & $89(90.8)$ & 1 & & 0.13 & 0.71 \\
\hline Yes & $8(8.2)$ & $9(9.2)$ & 0.88 & $0.75-1.56$ & & \\
\hline \multicolumn{7}{|c|}{ Hypertension } \\
\hline No & $71(72.4)$ & $71(72.4)$ & 1 & & 0.016 & 0.92 \\
\hline Yes & $27(27.6)$ & $27(27.6)$ & 1 & $0.75-1.5$ & & \\
\hline \multicolumn{7}{|c|}{ Allergy or asthma } \\
\hline $\mathrm{No}$ & $76(77.6)$ & $85(86.7)$ & 1 & & 1.94 & 0.06 \\
\hline Yes & $22(22.4)$ & $13(13.3)$ & 1.54 & $1.3-2.2$ & & \\
\hline \multicolumn{7}{|l|}{ Tuberculosis } \\
\hline No & $90(91.8)$ & 94 (95.9) & 1 & & 2.45 & 0.01 \\
\hline Yes & $8(8.2)$ & $4(4.1)$ & 2.08 & $1.65-4.08$ & & \\
\hline \multicolumn{7}{|c|}{ Diabetes mellitus } \\
\hline No & $90(91.8)$ & $89(90.8)$ & 1 & & 0.13 & 0.71 \\
\hline Yes & $8(8.2)$ & $9(9.2)$ & 0.88 & $0.79-1.58$ & & \\
\hline \multicolumn{7}{|l|}{ Thyroid } \\
\hline No & 95 (96.9) & $96(97.9)$ & 1 & & 0.45 & 0.49 \\
\hline Yes & $3(3.1)$ & $2(2.1)$ & 0.74 & $0.32-0.95$ & & \\
\hline \multicolumn{7}{|c|}{ Coronary heart } \\
\hline No & $84(85.7)$ & 85 (86.7) & 1 & & 0.078 & 0.81 \\
\hline Yes & $14(14.3)$ & $13(13.3)$ & 0.79 & $0.5-1.12$ & & \\
\hline \multicolumn{7}{|c|}{ Nephrolithiasis } \\
\hline No & $87(88.8)$ & $89(90.8)$ & 1 & & 1.67 & 0.11 \\
\hline Yes & $11(11.2)$ & $9(9.2)$ & 0.93 & $0.58-1.69$ & & \\
\hline \multicolumn{7}{|c|}{ Sexually transmitted } \\
\hline None & $82(83.7)$ & $85(86.7)$ & 0.78 & $0.38-1.08$ & - & - \\
\hline Gonorrhea & $11(11.2)$ & $9(9.2)$ & 0.91 & $0.8-1.58$ & 0.62 & 0.41 \\
\hline Other & $5(5.1)$ & $4(4.1)$ & 0.92 & $0.79-1.95$ & 0.04 & 0.81 \\
\hline
\end{tabular}

Received March 15, 2015; accepted November 03, 2015.

Rasool Roozegar

Department of Statistics

Yazd University, Yazd, Iran

Alireza Khoshdel

Department of Epidemiology

Aja University of Medical Sciences, Tehran, Iran 
452 Using Unconditional Logistic Regression to Assess Prostate Cancer Risk Factors: Practical Messages for Public Health 